Check for updates

Cite this: RSC Adv., 2017, 7, 35297

Received 5th May 2017

Accepted 8th July 2017

DOI: $10.1039 / c 7 r a 05059 c$

rsc.li/rsc-advances

\section{Vulpinic acid contributes to the cytotoxicity of Pulveroboletus ravenelii to human cancer cells by inducing apoptosis $\uparrow$}

\author{
Sil Kim,,$^{a}$ Hae Min So, $\$^{a}$ Hyun-Soo Roh, $\$^{b}$ Jin Kim, ${ }^{a}$ Jae Sik Yu, ${ }^{a}$ Seul Lee, ${ }^{b}$ \\ Soonja Seok, ${ }^{c}$ Changhyun Pang, ${ }^{d}$ Kwan-Hyuck Baek (D) ${ }^{* b}$ and Ki Hyun Kim (D) *a
}

Pulveroboletus ravenelii (Berk. et Curt.) Murr. (Boletaceae), commonly known as Ravenel's bolete, is an edible mushroom that is widely distributed in Korea, Japan, and China. P. ravenelii is used in traditional Chinese medicine and also to create color dyes. In this study, we explored the pharmacological activity of the fruiting bodies of $P$. ravenelii and found that their $\mathrm{MeOH}$ extracts showed cytotoxic activity in vitro against a variety of human cancer cells, including four lung adenocarcinoma cell lines (A549, $\mathrm{NCl}$ H1264, NCl-H1299, and Calu-6), two pancreatic ductal adenocarcinoma cell lines (PANC-1 and MIA $\mathrm{PaCa}-2$ ), and a hepatocellular carcinoma cell line (Hep G2), by inducing apoptosis. Based on the bioactivity-guided fractionation to identify the fraction with the highest cytotoxic activity, chemical investigation of the $\mathrm{MeOH}$ extract of the fruiting bodies of $P$. ravenelii led to the isolation of vulpinic acid (VA) (1) as the main component of the most cytotoxic fraction, the hexane-soluble fraction. Treatment with VA significantly reduced cell viability by inducing apoptotic cell death in all human cancer cell lines tested, with $\mathrm{IC}_{50}$ values ranging from 21.65 to $146.17 \mu \mathrm{M}$. These findings provide experimental evidence for a novel biological activity of $P$. ravenelii against human cancer cells. We also identified VA as the main constituent that contributes to the cytotoxic activity of $P$. ravenelii, thus raising the possibility of using $P$. ravenelii as a functional food as well as a source of lead compounds for the development of novel drugs for cancer prevention and management.

\section{Introduction}

Cancer is a group of diseases characterized by uncontrolled cell growth, nearby tissue invasion, and metastasis to various organs of the body through the blood and lymphatic systems. Now the second leading cause of global death, cancer was responsible for 8.7 million deaths in 2015. ${ }^{\mathbf{1 , 2}}$ Since the Vinca alkaloids vinblastine and vincristine, isolated from Catharanthus roseus, were found to be cytotoxic against human cancer cells in 1958, natural products have been potential resources for

\footnotetext{
${ }^{a}$ School of Pharmacy, Sungkyunkwan University, Suwon 440-746, Republic of Korea. E-mail: khkim83@skku.edu; Fax: +82-31-290-7730; Tel: +82-31-290-7700

${ }^{b}$ Department of Molecular and Cellular Biology, Samsung Biomedical Research Institute, Sungkyunkwan University School of Medicine, Suwon 440-746, Republic of Korea. E-mail: khbaek@skku.edu; Fax: +82-31-299-6169; Tel: +82-31-299-6162

${ }^{c}$ Agricultural Microbiology Division, National Institute of Agricultural Sciences, RDA, 166, Nongsaengmyeong-ro, Iseo-myeon, Wanju-gun, Jeollabuk-do 55365, Republic of Korea

${ }^{d}$ School of Chemical Engineering, Sungkyunkwan University, Suwon 440-746, Republic of Korea

$\dagger$ Electronic supplementary information (ESI) available: Representative bright-field images and representative immunofluorescence images of TUNEL staining. See DOI: $10.1039 / \mathrm{c} 7 \mathrm{ra05059c}$

$\$$ These authors contributed equally to this work.
}

lead compounds for therapeutic intervention in cancer. ${ }^{3-5}$ In the last few decades, mushrooms (i.e. the fruiting bodies of fungi) have emerged as potential pharmaceutical resources of compounds with various anticancer activities, including cytotoxicity against cancer cells and angiostatic activity. ${ }^{6}$ Therefore, it is important for cancer prevention and treatment to identify the main constituents of mushrooms exhibiting anti-cancer activity and evaluate their therapeutic potential.

Pulveroboletus ravenelii (Berk. et Curt.) Murr., commonly known as Ravenel's bolete or powdery sulfur bolete, is a mushroom belonging to the family Boletaceae, which is widely distributed in Korea, Japan, China, Hong Kong, Singapore, and North America. $P$. ravenelii matures from summer to fall, and the fruiting bodies are scattered or gathered on the ground of coniferous and broad-leaved forests. Interestingly, after injury the mushroom turns greenish blue and then grayish brown. $P$. ravenelii is edible ${ }^{7-9}$ and has been used in Chinese traditional medicine for the treatment of pain, stiffness, and bleeding. ${ }^{10} P$. ravenelii is also used in mushroom-based dyes to produce the colors yellow, gold, greenish yellow, orange, and olive. Previous studies demonstrated that the extract of $P$. ravenelii showed antibacterial activity against Bacillus subtilis, Micrococcus luteus, ${ }^{\mathbf{1 1}}$ and methicillin-susceptible and methicillin-resistant Staphylococcus aureus. ${ }^{12}$ Chemical investigations of $P$. ravenelii 
have shown that the mushroom contains diverse phenolic compounds with unique structures including vulpinic acid, atrometic acid, isoxerocomic acid, variegatic acid, xerocomorubin and variegatorubin from Australian $P$. ravenelii; vulpinic acid, permethyl ethers of methyl xerocomate, methyl atrometate, ravenelone, and isoravenelone from Japanese $P$. ravenelii; and pulveraven A and pulveraven B from North American $P$. ravenelii. ${ }^{11-14}$ Although several studies have been conducted on the pharmacological properties and chemistry of $P$. ravenelii extracts, the anti-cancer activities of $P$. ravenelii against human cancer cells and the underlying mechanisms of these activities have not been reported to date. Moreover, the specific cytotoxic compounds in $P$. ravenelii have not yet been identified.

In the present study, as part of our continuing efforts to discover anti-proliferative secondary metabolites from Korean wild mushrooms, ${ }^{15-20}$ we investigated the anti-proliferative constituents from a $\mathrm{MeOH}$ extract of the fruiting bodies of $P$. ravenelii using a bioactivity-guided isolation technique. We explored the effect of treating human cell lines with the $\mathrm{MeOH}$ extract of $P$. ravenelii, including lung adenocarcinoma, pancreatic ductal adenocarcinoma, and hepatocellular carcinoma cell lines, and found that the $\mathrm{MeOH}$ extract significantly reduced the viability of these cell lines by inducing apoptosis. Bioactivity-guided fractionation based on cytotoxic activity and chemical investigation of the active fraction revealed that the main constituent of the fraction, vulpinic acid, accounted for the cytotoxicity of the $P$. ravenelii $\mathrm{MeOH}$ extract to human cancer cell lines. Here, we present the cytotoxic effects of $P$. ravenelii on human cancer cells in vitro and identification of the active compound responsible for these effects.

\section{Results}

\section{The $P$. ravenelii $\mathrm{MeOH}$ extract shows cytotoxic activity against} human cancer cell lines

Fresh fruiting bodies of $P$. ravenelii were collected at Mt. Cheonggye (Seongnam, Korea) in the summer and dried for extraction. The dried samples were extracted with $80 \%$ aqueous $\mathrm{MeOH}$ at room temperature and the extract was concentrated in vacuo to obtain a crude $\mathrm{MeOH}$ extract.

To examine whether the $\mathrm{MeOH}$ extract affects cell proliferation and viability of human cancer cells in vitro, we treated four human adenocarcinoma cell lines (A549, NCI-H1264, NCIH1299 and Calu-6), two human pancreatic ductal adenocarcinoma cell lines (PANC-1 and MIA PaCa-2), and a human hepatocellular carcinoma cell line (Hep G2) with the extract for $48 \mathrm{~h}$ and then assessed mitochondrial dehydrogenase activity, an indicator of cell viability, ${ }^{21}$ using the WST-1 assay (Fig. 1). Interestingly, upon treatment with the $\mathrm{MeOH}$ extract, the amount of viable cells was significantly reduced in all human cancer cell lines tested. Moreover, the cancer cells showed dramatic morphological changes (Fig. 1A), such as cell shrinkage, rounding up, membrane blebbing, and detachment from the substratum, all of which are typical morphological features of apoptotic cells. ${ }^{22}$ In addition, the WST-1 assay revealed that the $\mathrm{MeOH}$ extract treatment significantly decreased the viability of all cancer cell lines in a dose-

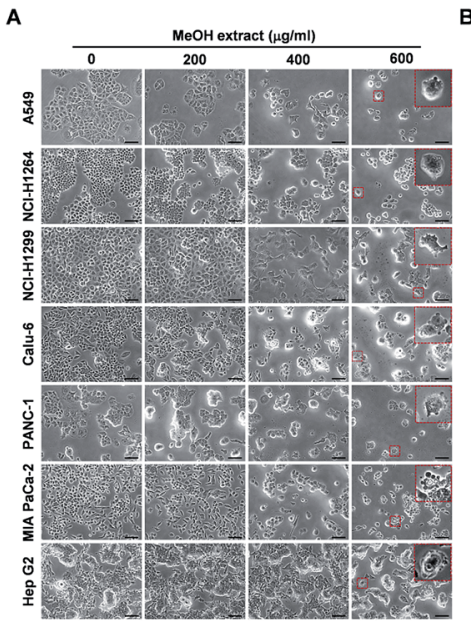

B

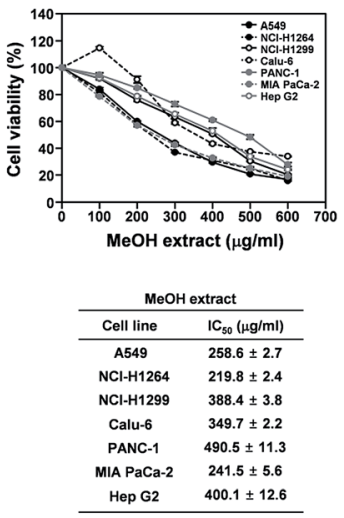

Fig. 1 Cytotoxic effects of the $P$. ravenelii $\mathrm{MeOH}$ extract on human lung adenocarcinoma, pancreatic ductal adenocarcinoma, and hepatocellular carcinoma cells. (A) Representative bright-field images (200x total magnification) of human cancer cells taken at $48 \mathrm{~h}$ after treatment with the $P$. ravenelii $\mathrm{MeOH}$ extract at the indicated concentrations. Magnified regions are shown as insets. (B) Viability of human cancer cell lines as assessed by the WST-1 assay after treatment with the $P$. ravenelii $\mathrm{MeOH}$ extract at the indicated concentrations (upper panels) and $I_{50}$ values of the extract for the corresponding cell line (lower panels). Data are representative of three independent experiments and are presented as means \pm SEMs. Scale bar: $100 \mu \mathrm{m}$

dependent manner, with $\mathrm{IC}_{50}$ values ranging from 219.8 to $490.5 \mu \mathrm{g} \mathrm{mL}^{-1}$ (Fig. 1B). These data suggest that the P. ravenelii $\mathrm{MeOH}$ extract has cytotoxic activity against human cancer cells and that this activity is sufficient to inhibit their growth in vitro.

The HX, MC, and EA fractions, but not the BuOH fraction, of the $P$. ravenelii $\mathrm{MeOH}$ extract exhibit cytotoxicity against human cancer cell lines

To identify the constituents of the $\mathrm{MeOH}$ extract of $P$. ravenelii responsible for its cytotoxic activity against human cancer cells, we separated the extract into several fractions by solventpartitioning with hexane ( $\mathrm{HX}$ ), $\mathrm{CH}_{2} \mathrm{Cl}_{2}$ (MC), EtOAc (EA), and $n$-BuOH, thereby yielding hexane, $\mathrm{CH}_{2} \mathrm{Cl}_{2}$, EtOAc, and $n-\mathrm{BuOH}$ soluble fractions. Each fraction was then assessed for its cytotoxic activity in human cancer cell lines using the WST-1 assay (Fig. 2). The EA, HX, and MC fractions, but not the $\mathrm{BuOH}$ fraction, exhibited cytotoxicity against all human cancer cell lines examined in a dose-dependent manner with the $\mathrm{IC}_{50}$ values ranging from 66.0 to $146.2,39.6$ to 133.3 , and 95.3 to 148.6 $\mu \mathrm{g} \mathrm{mL} \mathrm{mL}^{-1}$, respectively (Fig. $2 \mathrm{~A}-\mathrm{G}$ and Table S1†). In addition, while treatment with the $\mathrm{BuOH}$ fraction failed to induce morphological changes in human cancer cells, cancer cells treated with the EA, HX, and MC fractions showed morphological alterations similar to those observed in cancer cells treated with the $\mathrm{MeOH}$ extract (Fig. S1 $\dagger$ ). These observations imply that the cytotoxic activity of the $P$. ravenelii $\mathrm{MeOH}$ extract against human cancer cell lines can be attributed to compounds contained in the EA, HX, and MC fractions, but not 


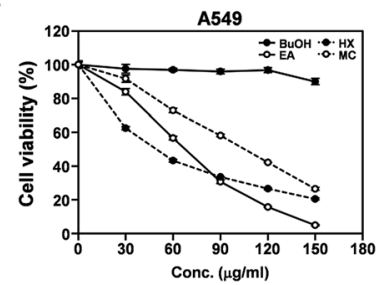

c

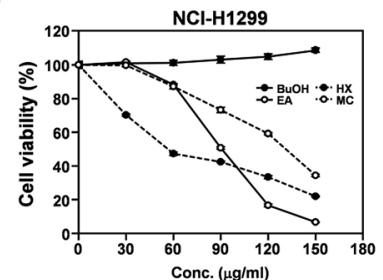

E
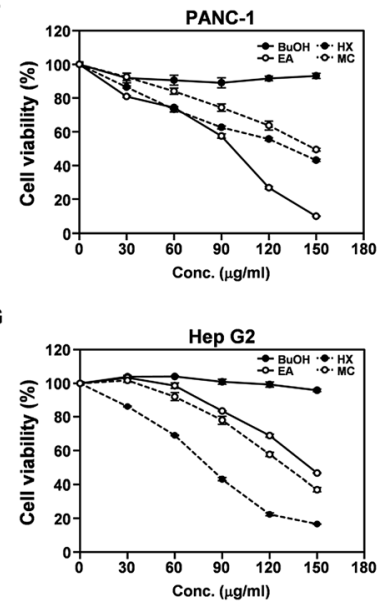
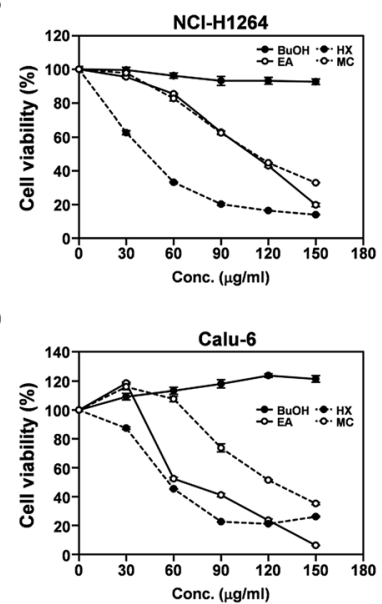

$\mathbf{F}$

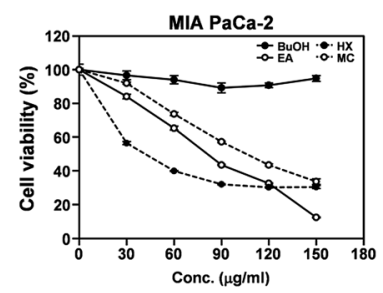

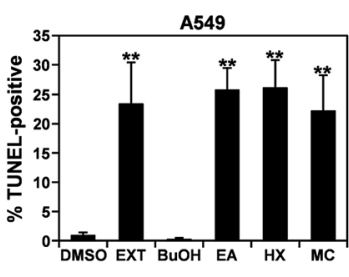

c

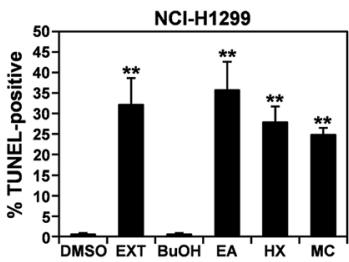

E

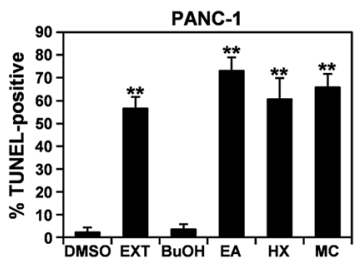

G

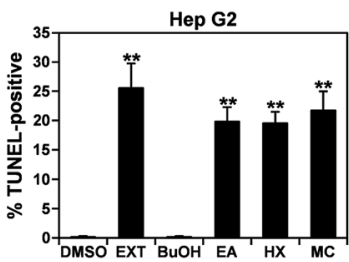

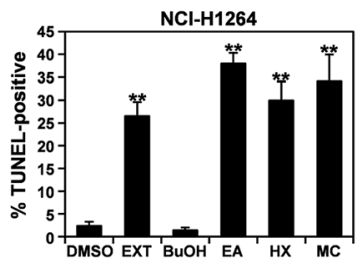

D

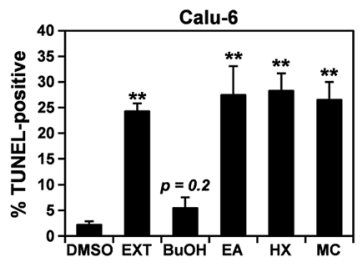

$\mathbf{F}$

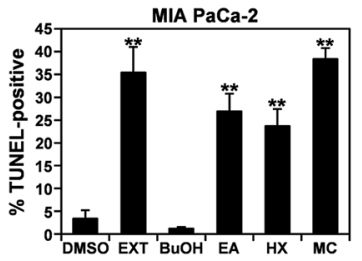

Fig. 2 Cytotoxic activity of the four different fractions prepared from the $P$. ravenelii $\mathrm{MeOH}$ extract against human lung adenocarcinoma, pancreatic ductal adenocarcinoma, and hepatocellular carcinoma cell lines. (A-G) Viability of A549 (A), NCl-H1264 (B), NCl-H1299 (C), Calu6 (D), PANC-1 (E), MIA PaCa-2 (F), and Hep G2 (G) cells as determined using the WST-1 assay after treatment with the $\mathrm{BuOH}, \mathrm{EA}, \mathrm{HX}$, and $\mathrm{MC}$ fraction of the $P$. ravenelii $\mathrm{MeOH}$ extract at the indicated concentrations for $48 \mathrm{~h}$. Data are representative of three independent experiments and are presented as means \pm SEMs.

in the $\mathrm{BuOH}$ fraction. In addition, the $\mathrm{HX}$ fraction showed the lowest $\mathrm{IC}_{50}$ values in all cancer cell lines tested (with the exception of PANC-1), raising the possibility that this fraction contains the most promising compounds with the highest cytotoxic activity against human cancer cells.

The $P$. ravenelii MeOH extract and its cytotoxic fractions induce apoptotic cell death in human cancer cell lines

Upon treatment with the $P$. ravenelii $\mathrm{MeOH}$ extract and its cytotoxic fractions, human cancer cells showed morphological changes similar to those observed in cells undergoing apoptosis (Fig. 1A and S1 $\dagger$ ). Therefore, to further confirm that the $\mathrm{MeOH}$ extract and its cytotoxic fractions reduced the viability of lung, pancreatic, and liver cancer cells by inducing apoptosis, apoptotic cell populations were assessed in the cancer cell lines using the TUNEL assay after treatment with the extracts at their

Fig. 3 The $\mathrm{MeOH}$ extract of $P$. ravenelii and its fractions induce apoptotic cell death in human lung adenocarcinoma, pancreatic ductal adenocarcinoma and hepatocellular carcinoma cells. (A-G) Quantitation of TUNEL-positive A549 (A), NCl-H1264 (B), NCl-H1299 (C), Calu-6 (D), PANC-1 (E), MIA PaCa-2 (F), and Hep G2 (G) cells after treatment with the $P$. ravenelii $\mathrm{MeOH}$ extract (EXT) and its fractions (EA, $\mathrm{HX}$, and $\mathrm{MC}$ ) at their $\mathrm{IC}_{50}$ concentrations for $48 \mathrm{~h}$. Cells treated with $0.15 \%$ DMSO in growth media or the $\mathrm{BuOH}$ fraction $\left(150 \mu \mathrm{g} \mathrm{mL} \mathrm{L}^{-1}\right)$ were also TUNEL-stained and counted as negative controls. Data are representative of three independent experiments and are presented as means \pm SEMs. ${ }^{* *} p<0.01$.

$\mathrm{IC}_{50}$ doses for $48 \mathrm{~h}$ (Fig. 3 and $\mathrm{S} 2 \dagger$ ). As expected, the percentages of TUNEL-positive cells were dramatically increased in all human cancer cell lines treated with the $\mathrm{MeOH}$ extract and its cytotoxic fractions (EA, HX, and MC) compared to their untreated controls, indicating that the potent cytotoxic activities of these fractions against human cancer cells are mediated by induction of apoptosis.

\section{Chemical analysis of the HX fraction identifies the active compound}

Based on our observation that the HX fraction exhibited the most cytotoxic activity out of all studied fractions of $P$. ravenelii $\mathrm{MeOH}$ extract, we next analyzed the HX fraction to identify the constituents that contribute to the cytotoxicity of $P$. ravenelii against human cancer cells in vitro. Chemical investigation of the HX fraction using repeated column chromatography and HPLC purification led to the isolation of its main compound, identified as vulpinic acid (VA) (1) (Fig. 4A) by comparison of its 


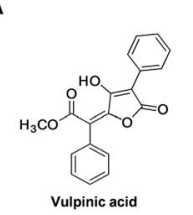

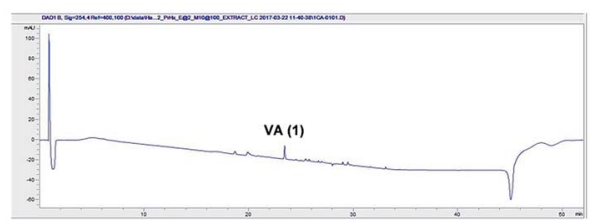

Fig. 4 Vulpinic acid (VA) is the major component of the most cytotoxic fraction, the HX fraction. (A) Chemical structure of VA. (B) UV chromatogram of LC/MS of the HX fraction (detection wavelength: $254 \mathrm{~nm})$

spectroscopic and physical data with reported values. ${ }^{12,14}$ Fig. $4 \mathrm{~B}$ shows a representative chromatogram from which it can be inferred that VA is the major constituent of the active HX fraction.

\section{VA exhibits cytotoxicity against human cancer cell lines}

A recent study showed that VA isolated from lichens exhibits cytotoxic effects against Hep G2 cells and NS20Y neuroblastoma cells. ${ }^{23}$ Hence, VA could be the main constituent contributing to the cytotoxicity of the $\mathrm{HX}$ fraction and the $P$. ravenelii $\mathrm{MeOH}$ extract against all human cancer cell lines examined in our study. To determine whether VA treatment is sufficient to suppress the growth of human lung, pancreatic, and liver cancer cells, we examined the effect of VA on the viability of A549, NCI-H1264, NCI-H1299, Calu-6, PANC-1, MIA PaCa-2, and Hep G2 cells using the WST-1 assay (Fig. 5). VA treatment significantly reduced cell viability in all cancer cell lines tested compared to their untreated controls (Fig. 5A) and decreased
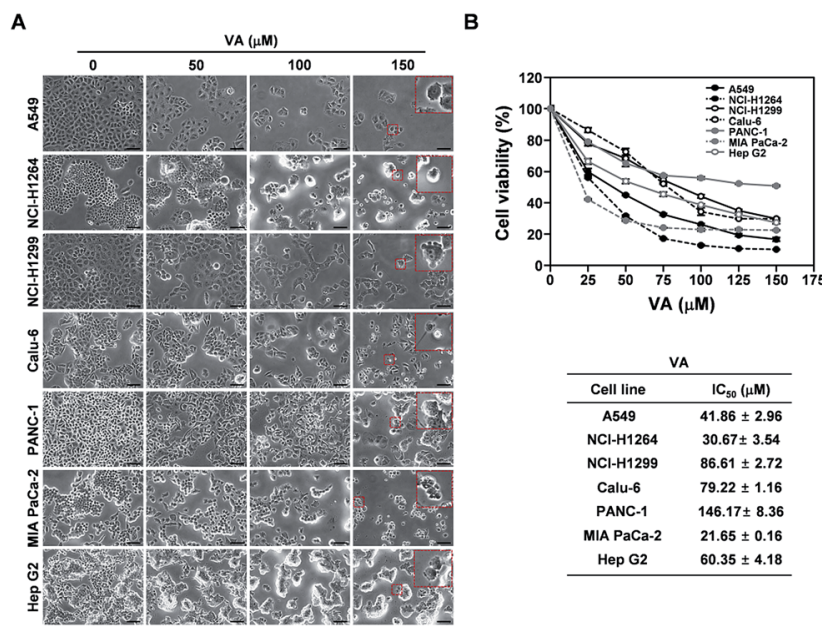

Fig. 5 Cytotoxic activity of vulpinic acid (VA) isolated from $P$. ravenelii against human lung adenocarcinoma, pancreatic ductal adenocarcinoma, and hepatocellular carcinoma cells. (A) Representative brightfield images (200 $\times$ total magnification) of human cancer cells taken at $48 \mathrm{~h}$ after treatment with VA at the indicated concentrations. Magnified regions are shown as insets. (B) Viability of human cancer cell lines as assessed by the WST-1 assay after treatment with VA at the indicated concentrations (upper panels) and the $I_{50}$ values of VA for the corresponding cancer cell lines (lower panels). Data are representative of three independent experiments and are presented as means \pm SEMs. Scale bar: $100 \mu \mathrm{m}$. cell viability in a dose-dependent manner, with $\mathrm{IC}_{50}$ values ranging from 21.65 to $146.17 \mu \mathrm{M}$ (Fig. 5B). These data imply that VA is the constituent of $P$. ravenelii responsible for its cytotoxicity against human cancer cells in vitro.

\section{VA induces apoptotic cell death in human cancer cell lines}

In all human cancer cell lines, VA treatment also resulted in the typical morphological changes observed in cells undergoing apoptosis. To verify the apoptotic activity of VA isolated from $P$. ravenelii on human cancer cells, we assessed apoptotic cell death in A549, NCI-H1264, NCI-H1299, Calu-6, PANC-1, MIA PaCa-2, and Hep G2 cells using the TUNEL assay after treating cells with VA at its $\mathrm{IC}_{50}$ concentration for $48 \mathrm{~h}$. We found that the percentage of TUNEL-positive cells was significantly increased in all cancer cell lines treated with VA compared with their untreated controls (Fig. 6).

VA-induced apoptosis in the cancer cells was further confirmed by detecting a cleaved form of PARP, an indicator of caspase activity, ${ }^{24}$ in NCI-H1264, NCI-H1299, Calu-6, and MIA PaCa-2 cell lines after VA treatment using immunoblotting (Fig. 7). In all cell lines, PARP cleavage was increased upon VA
A

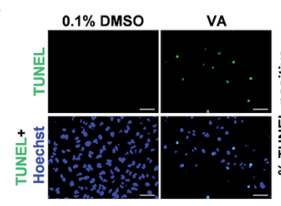

C
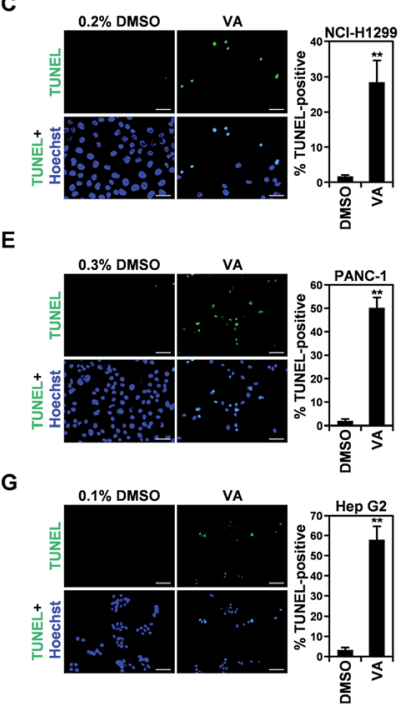

B
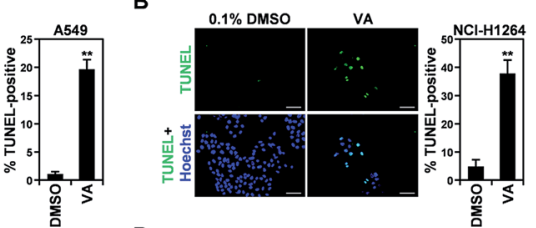

D

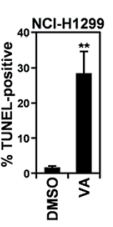

$\mathbf{F}$

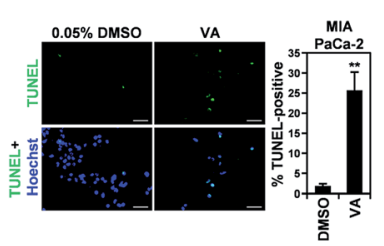

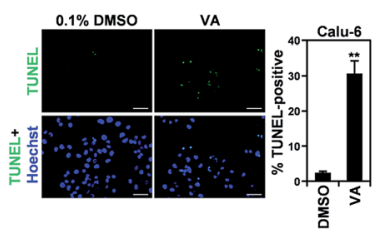

Fig. 6 Vulpinic acid (VA) increases the apoptotic cell population in human lung adenocarcinoma, pancreatic ductal adenocarcinoma, and hepatocellular carcinoma cell lines. (A-G) Representative fluorescence images (400 $\times$ total magnification) of TUNEL staining (left panel) and quantitation of TUNEL-positive cells (right panel) in A549 (A), NClH1264 (B), NCl-H1299 (C), Calu-6 (D), PANC-1 (E), MIA PaCa-2 (F), and Hep G2 (G) cells after treatment with $V A$ at the respective $I C_{50}$ concentrations for $48 \mathrm{~h}$. Cells treated with 0.05 to $0.3 \%$ DMSO in growth media were also TUNEL-stained as negative controls. Data are representative of three independent experiments and are presented as means \pm SEMs. Scale bar: $50 \mu \mathrm{m} .{ }^{* * p}<0.01$. 


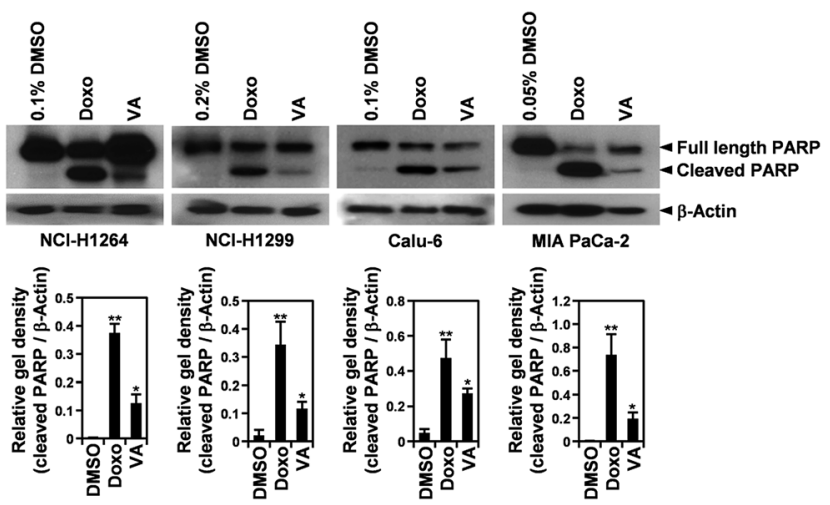

Fig. 7 Vulpinic acid (VA) induces PARP cleavage in human lung adenocarcinoma and pancreatic ductal adenocarcinoma cell lines. Whole cell lysates were prepared from NCl-H1264, NCl-H1299, Calu6 , and MIA PaCa-2 cells treated with VA at the respective $I_{50}$ concentrations or $1 \mu \mathrm{M}$ doxorubicin (Doxo) as a positive control. The membranes were probed for PARP and $\beta$-actin as a loading control. Data are representative of three independent experiments and are presented as means \pm SEMs. $* p<0.05, * * p<0.01$.

treatment, further supporting the TUNEL assay data that VA induces apoptotic cell death in human cancer cells.

Taken together, these results suggest that VA has cytotoxic activity against human cancer cells, that this activity involves the induction of apoptosis, and that VA is one of the constituents of $P$. ravenelii contributing to its cytotoxicity to human cancer cell lines.

\section{Discussion}

Recently, mushrooms were shown to be plentiful resources of novel compounds with various pharmaceutical activities such as anti-cancer, antiviral, anti-oxidant, anti-diabetic, and immunomodulatory activities. ${ }^{6,25,26}$ In particular, edible mushrooms showing anti-cancer activities and the active compounds of these mushrooms are thought to be promising alternatives for anti-cancer drugs currently used in clinics, since they may have fewer various adverse effects and complications. Therefore, screening mushrooms with anti-cancer properties and identifying the compounds responsible for these properties could potentially reduce the side effects of cancer treatment and help cancer prevention efforts. In this context, our group collected endemic mushroom species in the mountainous regions during a hot humid summer. We also prepared $\mathrm{MeOH}$ extracts of these species to test in our cytotoxic screening system and conducted further chemical analysis of the identified cytotoxic $\mathrm{MeOH}$ extracts to discover the anti-proliferative secondary metabolites of Korean wild mushrooms. ${ }^{15-20}$ Recent studies successfully identified lead compounds with potential cytotoxic activities against various types of cancer as well as antiantigenic properties from mushrooms. ${ }^{27-31}$ For example, cucurbitane triterpenes isolated from Leucopaxillus gentianeus were found to have significant anti-proliferative activity against human large-cell lung carcinoma cells. ${ }^{27}$ Moreover, ergone identified from Fulviformes fastuosus had promising cytotoxic activity against human muscle rhabdomyosarcoma and hepatocellular carcinoma cells by inducing apoptosis. ${ }^{28} \mathrm{~A}$ recent study also identified two novel triterpenoids from Naematoloma fasciculare and validated their significant cytotoxicity against various cancer cell lines, including human lung adenocarcinoma, ovarian carcinoma, melanoma, and colorectal adenocarcinoma cell lines. ${ }^{29}$ In addition, the $\mathrm{MeOH}$ extract of Phellinus linteus was demonstrated to have angiostatic activity both in vitro and in vivo. ${ }^{30}$ Furthermore, oral administration of mycelial cultures of $P$. linteus was shown to attenuate the growth of human hepatoma xenografts in mice by enhancing antitumor immune responses. ${ }^{31}$

Previous chemical and biological investigations of $P$. ravenelii revealed several novel compounds, including isoravenelone, ravenelone, pulveraven $\mathrm{A}$, and pulveraven $\mathrm{B}$, as well as the known compound, vulpinic acid (VA). ${ }^{12,14}$ However, the pharmaceutical activities of this mushroom, such as its anticancer activity, still remain to be elucidated. We found that the $P$. ravenelii $\mathrm{MeOH}$ extract exhibited cytotoxic activity in vitro against various types of human cancer cells, including lung, pancreatic, and liver cancer cells, by inducing apoptotic cell death. Although the $\mathrm{MeOH}$ extract showed a high $\mathrm{IC}_{50}$ value (490.5 $\mu \mathrm{g} \mathrm{mL} \mathrm{m}^{-1}$ ) against PANC-1 cells, the other human pancreatic cancer cell line, MIA PaCa-2, was found to be sensitive to the extract with an $\mathrm{IC}_{50}$ value of $241.5 \mu \mathrm{g} \mathrm{mL}{ }^{-1}$. This was comparable to the $\mathrm{IC}_{50}$ values of other human cancer cell types tested, indicating that the genetic diversity of cancer cells, but not their cancer type, affects the cytotoxicity of the $P$. ravenelii $\mathrm{MeOH}$ extract. In addition, treatment with the $\mathrm{MeOH}$ extract increased apoptosis and decreased cell viability in human cancer cell lines harboring wild-type p53 (A549 and Hep G2), as well as in cell lines with mutant $p 53$ (NCI-H1264, PANC-1 and MIA PaCa-2) or null-p53 (NCI-H1299 and Calu-6). ${ }^{32-35}$ Moreover, the $\mathrm{IC}_{50}$ values did not show any significant correlation with the p53 status of the corresponding cell lines, demonstrating that p53 status in human cancer cells does not affect the cytotoxic potential of the extract.

All fractions of the $P$. ravenelii $\mathrm{MeOH}$ extract showed cytotoxicity against human cancer cell lines, with the exception of the $\mathrm{BuOH}$ fraction. Further chemical investigation of the $\mathrm{HX}$ fraction, which was the most cytotoxic to most of the cell lines examined, revealed that the main component of this fraction was VA (1). VA is an important secondary metabolite in lichens and is also found in some mushroom species such as Scleroderma citrinum..$^{\mathbf{1 2 , 1 4 , 2 3 , 3 6 , 3 7}}$ VA has also been shown to exhibit antiproliferative activity against human hepatocellular carcinoma (Hep G2), neuroblastoma (NS20Y), and retinoblastoma (NCIH187) cell lines and to induce apoptosis in Hep G2 cells. ${ }^{23,36,37}$ In our study, VA isolated from $P$. ravenelii was also demonstrated to have cytotoxic activity, with $\mathrm{IC}_{50}$ values ranging from 21.65 to $146.17 \mu \mathrm{M}$. VA also had apoptotic activity against seven different human cancer cell lines, further supporting the idea that VA is potentially a lead compound for therapeutic interventions in cancer.

The cytotoxic activities of VA in the human cancer cell lines were similar to those of the $\mathrm{HX}$ fraction and the $P$. ravenelii $\mathrm{MeOH}$ extract in the corresponding cell lines, suggesting that 
VA is the main constituent contributing to the cytotoxicity of the $P$. ravenelii $\mathrm{MeOH}$ extract against human cancer cell lines. However, the MC and EA fractions of the $\mathrm{MeOH}$ extract were also found to exhibit cytotoxicity against human cancer cell lines, indicating that constituents of $P$. ravenelii other than VA might also have cytotoxic potential and contribute to its cytotoxic activity against human cancer cell lines in vitro. Thus, further studies aimed at identifying and validating the cytotoxic compounds contained in those fractions will be necessary to fully understand the cytotoxic effects of $P$. ravenelii on human cancer cells. In addition, we showed that the cytotoxicity of VA, the $P$. ravenelii $\mathrm{MeOH}$ extract, and its fractions was mediated by apoptosis. Considering that VA treatment increased the level of the cleaved form of PARP, it is likely that VA elicits apoptotic cell death in human cancer cells by activating caspase-3 and/or caspase-7. ${ }^{24,38-41}$ However, the underlying mechanisms need to be further investigated to uncover the full cytotoxic potential of VA and $P$. ravenelii against human cancer cells.

\section{Experimental}

\section{General experimental procedures}

Optical rotation was measured on a Jasco P-1020 polarimeter. IR spectra were recorded on a Bruker IFS-66/S FT-IR spectrometer. UV spectra were acquired on an Agilent 8453 UV-visible spectrophotometer. LC/MS analysis was performed on an Agilent 1200 Series HPLC system equipped with a diode array detector and a 6130 Series ESI mass spectrometer using an analytical Kinetex column $(2.1 \times 100 \mathrm{~mm}, 5 \mu \mathrm{m})$. NMR spectra were recorded on a Bruker AVANCE III 700 NMR spectrometer operating at $700 \mathrm{MHz}\left({ }^{1} \mathrm{H}\right)$ and $175 \mathrm{MHz}\left({ }^{13} \mathrm{C}\right)$. Preparative HPLC used a Waters 1525 binary HPLC pump with a Waters 996 photodiode array detector. Semi-preparative HPLC used a Shimadzu Prominence HPLC System with SPD-20A/20AV Series Prominence HPLC UV-Vis detectors. Column chromatography was performed with a silica gel 60 column (Merck, 230-400 mesh) and an RP-C18 silica gel column (Merck, 230-400 mesh). Merck precoated silica gel F254 plates and reversed-phase (RP)18 F254s plates were used for TLC. Spots were detected on TLC under UV light or by heating after spraying with anisaldehydesulphuric acid.

\section{Mushroom material}

Fresh fruiting bodies of $P$. ravenelii were collected at Mt. Cheonggye, Seongnam (Gyeonggi-do, Korea) in August 2014. A voucher specimen (HCCN26437) of the mushroom was authenticated by one of the authors (S. Seok) and deposited at the Herbarium Conservation Center of the National Institute of Agricultural Sciences (HCCN), RDA Korea.

\section{Extraction and isolation of compounds}

Fresh fruiting bodies of $P$. ravenelii (450 g) were air-dried and extracted with $80 \%$ aqueous $\mathrm{MeOH}(3.0 \mathrm{~L}$ each $\times 3$ days) three times at room temperature, after which the extracts were filtered using Whatman filter paper no. 2 (pore size: $8 \mu \mathrm{m}$ ). The filtrates were combined and concentrated in vacuo, thus yielding $12.7 \mathrm{~g}$ of crude $\mathrm{MeOH}$ extract. The extract was dissolved in distilled water $(700 \mathrm{~mL})$ and successively solvent-partitioned in hexane (HX), $\mathrm{CH}_{2} \mathrm{Cl}_{2}$ (MC), EtOAC (EA), and $n-\mathrm{BuOH}(700 \mathrm{~mL}$ $\times 3$ ), thereby generating hexane ( $0.4 \mathrm{~g}), \mathrm{CH}_{2} \mathrm{Cl}_{2}(1.0 \mathrm{~g})$, EtOAC $(0.9 \mathrm{~g})$, and $n$ - $\mathrm{BuOH}(2.1 \mathrm{~g})$ miscible fractions. The $\mathrm{MeOH}$ extract and each fraction thereof were then dissolved in dimethyl sulfoxide (DMSO, Sigma, St. Louis, MO, USA) as stock solutions and evaluated for their cytotoxic activity against human cancer cell lines.

To discover the cytotoxic chemical constituents, the hexanesoluble fraction $(0.4 \mathrm{~g})$ exhibiting the most cytotoxic activity was further separated by silica gel column (230-400 mesh) chromatography with a hexane-EtOAc gradient solvent system (10:1 to $1: 1)$ to produce nine fractions (H1-H9). Fraction H7 (43.1 $\mathrm{mg}$ ) was then separated by reversed phase semipreparative HPLC on a Phenomenex Luna column (phenylhexyl, $250 \times 10.0 \mathrm{~mm}, 5 \mu \mathrm{m}$, flow rate: $2 \mathrm{~mL} \mathrm{~min}^{-1}$ ) using a gradient system of acetonitrile-water ( $4: 6$ to $1: 0)$, thereby generating compound 1 ( $\left.8.9 \mathrm{mg}, t_{\mathrm{R}}=36.0 \mathrm{~min}\right)$. Fraction $\mathrm{H} 8$ (45.2 $\mathrm{mg}$ ) was separated by the same HPLC system using a gradient system of acetonitrile-water ( $2: 8$ to $8: 2)$, thereby also generating compound $1\left(12.6 \mathrm{mg}, t_{\mathrm{R}}=34.5 \mathrm{~min}\right)$. The resultant compound $\mathbf{1}$ was then dissolved in DMSO as a stock solution and tested for its cytotoxicity against human cancer cell lines.

\section{LC/MS analysis of the hexane-soluble fraction}

The hexane-soluble fraction of the $P$. ravenelii $\mathrm{MeOH}$ extract was analyzed by LC/MS using vulpinic acid (VA), which was isolated from $P$. ravenelii, as a marker compound. Stock solutions of VA and the hexane-soluble fraction were prepared by dissolving $1 \mathrm{mg}$ of sample in $1 \mathrm{~mL} \mathrm{MeOH}$. Each solution was further diluted with $\mathrm{MeOH}$ to a concentration of $100 \mu \mathrm{g} \mathrm{mL} \mathrm{m}^{-1}$. The solutions were filtered through a $0.45 \mathrm{~mm}$ hydrophobic PTFE filter and finally analyzed by LC/MS using a LC-MS Agilent 1200 Series analytical system (Agilent Technologies, Santa Clara, CA, USA) equipped with a photodiode array (PDA) detector linked to a 6130 Series ESI mass spectrometer. Analysis was performed by injection of $10 \mu \mathrm{L}$ of each sample onto a Kinetex C18 column $(2.1 \times 100 \mathrm{~mm}, 5 \mu \mathrm{m}$; Phenomenex, Torrance, CA, USA $)$ set at $25{ }^{\circ} \mathrm{C}$. The mobile phase consisted of formic acid in $\mathrm{H}_{2} \mathrm{O}[0.1 \%$ $(\mathrm{v} / \mathrm{v})]$ (A) and $\mathrm{MeOH}(\mathrm{B})$ was delivered at a flow rate of $0.3 \mathrm{~mL}$ $\min ^{-1}$ by applying the following programmed gradient elution: $10-100 \%$ (B) for $50 \mathrm{~min}$, to perform post-run reconditioning of the column.

\section{Cell culture}

The human lung adenocarcinoma cell lines, A549, NCI-H1264, NCI-H1299 and Calu-6, were kindly provided by Dr Steven M. Albelda (University of Pennsylvania School of Medicine, Philadelphia, PA, USA). The human pancreatic ductal adenocarcinoma cell lines, PANC-1 and MIA PaCa-2, and the human hepatocellular carcinoma cell line, Hep G2, were obtained from the American Type Culture Collection (ATCC, Rockville, MD, USA). All the cell lines were grown in RPMI-1640 medium supplemented with 10\% FBS (Hyclone, Logan, UT, USA), $2 \mathrm{mM} \mathrm{L}^{-}$ 
glutamine (Gibco BRL, Grand Island, NY, USA), $50 \mathrm{U} \mathrm{mL}^{-1}$ penicillin, and $50 \mu \mathrm{g} \mathrm{mL}^{-1}$ streptomycin (WelGENE, Seoul, Korea), and maintained at $37^{\circ} \mathrm{C}$ in a humidified atmosphere of $5 \% \mathrm{CO}_{2}$.

\section{Cell viability analysis}

A total of $5 \times 10^{3}$ cells per well were plated in triplicate in 96well tissue culture plates (Thermo Scientific, Waltham, MA, USA) and treated with the $P$. ravenelii $\mathrm{MeOH}$ extract, its fractions, and VA isolated from the hexane-soluble fraction at various concentrations for $48 \mathrm{~h}$. Cells treated with 0.05 to $0.6 \%$ DMSO corresponding to the percentages of DMSO in cell cultures treated with the extract, its fractions and VA were used as vehicle controls. The cell viability was then assessed by the WST-1 cell proliferation assay following the manufacturer's instructions (Daeil Lab Service, Seoul, Korea) and determined as a percentage of vehicle control. $\mathrm{IC}_{50}$ values were calculated by non-linear regression analysis using GraphPad Prism 5.0 (GraphPad Software, Inc., San Diego, CA, USA).

\section{TUNEL assay}

Cells were seeded on $12 \mathrm{~mm}$ coverslips $\left(7.5 \times 10^{3}\right.$ cells per coverslip) and then treated with the $\mathrm{MeOH}$ extract of $P$. ravenelii, its fractions, and VA isolated from the hexane-soluble fraction at their $\mathrm{IC}_{50}$ concentrations for $48 \mathrm{~h}$. Cells treated with DMSO were used as vehicle controls. Apoptotic human cancer cells were then assessed by terminal deoxyribonucleotidyl transferase-mediated dUTP nick end labeling (TUNEL) staining using the Dead-End labeling kit (Promega, Madison, WI, USA) following the manufacturer's instructions. After counterstaining with $1 \mu \mathrm{g} \mathrm{mL}{ }^{-1}$ Hoechst dye (Sigma) to visualize cell nuclei, cells were examined under a fluorescence microscope (Carl Zeiss, Jena, Germany). The percentage of apoptotic cells was then determined as the number of TUNEL-positive cells divided by the total number of cells counted in six randomly selected high-power fields $(400 \times)$ on each slide.

\section{Immunoblotting}

Cells were plated in $10 \mathrm{~cm}$ tissue culture dishes $\left(10^{6}\right.$ cells per dish; Thermo Scientific), grown overnight, and treated with the $\mathrm{MeOH}$ extract of $P$. ravenelii, its fractions, and VA isolated from the hexane-soluble fraction at their $\mathrm{IC}_{50}$ concentrations for $48 \mathrm{~h}$ or $1 \mu \mathrm{M}$ doxorubicin (Sigma) as a positive control. Cells treated with DMSO were used as vehicle controls. At $48 \mathrm{~h}$ after treatment, cells were harvested and lysed with RIPA buffer supplemented with $10 \mathrm{mM} \mathrm{NaF}, 1 \mathrm{mM} \mathrm{Na}_{3} \mathrm{VO}_{4}, 1 \mu \mathrm{M}$ DTT, $1 \mathrm{mM}$ PMSF (Sigma) and a protease inhibitor cocktail (Roche, Mannheim, Germany). Proteins in the whole cell lysates were then separated by SDS-PAGE and transferred to PVDF membranes (Bio-Rad, Hercules, CA, USA). The membranes were probed with antipoly (ADP-ribose) polymerase (PARP) antibodies (Cell Signaling Technology, Danvers, MA, USA). $\beta$-Actin (Thermo Scientific) was used as a loading control. To determine relative gel densities, band densities were quantified with densitometric analysis using Image software (NIH, Bethesda, MD, USA) and then normalized to $\beta$-actin as previously described. ${ }^{42}$

\section{Statistical analysis}

Student's two-tailed unpaired $t$ test was used to determine the statistical significance of differences between cells treated with the $\mathrm{MeOH}$ extract of $P$. ravenelii, its fractions, or VA isolated from the hexane-soluble fraction versus vehicle controls. Data are presented as means \pm SEMs and $p$ values less than 0.05 were considered statistically significant.

\section{Conclusions}

The data presented here indicate that $P$. ravenelii has cytotoxic activity against human cancer cells by inducing apoptosis. We also identified VA as the main constituent of the HX fraction, which was the most cytotoxic fraction of the P. ravenelii $\mathrm{MeOH}$ extract, and found that VA is one of the main constituents contributing to the cytotoxicity of this mushroom to human cancer cells. To the best of our knowledge, our study is the first to demonstrate the cytotoxic activity of $P$. ravenelii against human cancer cells. Moreover, our results suggest that $P$. ravenelii and its main constituent VA are potentially useful as a functional food and a lead compound, respectively, for cancer prevention and treatment.

\section{Acknowledgements}

This research was supported by the Basic Science Research Program through the National Research Foundation of Korea (NRF), which is funded by the Ministry of Science, ICT, \& Future Planning (2015R1C1A1A02037383), and by the Ministry of Education (NRF-2012R1A5A2A28671860). Seul Lee was supported by the NRF-2015-Global PhD Fellowship Program of the National Research Foundation of Korea (NRF), which is funded by the Korean Government (NRF-2015H1A2A1034135).

\section{References}

1 D. Hanahan and R. A. Weinberg, Cell, 2011, 144, 646-674.

2 C. Fitzmaurice, C. Allen, R. M. Barber, L. Barregard, Z. A. Bhutta, H. Brenner, D. J. Dicker, O. Chimed-Orchir, R. Dandona, L. Dandona, T. Fleming, M. H. Forouzanfar, J. Hancock, R. J. Hay, R. Hunter-Merrill, C. Huynh, H. D. Hosgood, C. O. Johnson, J. B. Jonas, J. Khubchandani, G. A. Kumar, M. Kutz, Q. Lan, H. J. Larson, X. Liang, S. S. Lim, A. D. Lopez, M. F. MacIntyre, L. Marczak, N. Marquez, A. H. Mokdad, C. Pinho, F. Pourmalek, J. A. Salomon, J. R. Sanabria, L. Sandar, B. Sartorius, S. M. Schwartz, K. A. Shackelford, K. Shibuya, J. Stanaway, C. Steiner, J. Sun, K. Takahashi, S. E. Vollset, T. Vos, J. A. Wagner, H. Wang, R. Westerman, H. Zeeb, L. Zoeckler, F. Abd-Allah, M. B. Ahmed, S. Alabed, N. K. Alam, S. F. Aldhahri, G. Alem, M. A. Alemayohu, R. Ali, R. AlRaddadi, A. Amare, Y. Amoako, A. Artaman, H. Asayesh, N. Atnafu, A. Awasthi, H. B. Saleem, A. Barac, N. Bedi, I. Bensenor, A. Berhane, E. Bernabe, B. Betsu, A. Binagwaho, D. Boneya, I. Campos-Nonato, C. Castaneda-Orjuela, F. Catala-Lopez, P. Chiang, C. Chibueze, A. Chitheer, 
J. Y. Choi, B. Cowie, S. Damtew, J. das Neves, S. Dey, S. Dharmaratne, P. Dhillon, E. Ding, T. Driscoll, D. Ekwueme, A. Y. Endries, M. Farvid, F. Farzadfar, J. Fernandes, F. Fischer, G. H. TT, A. Gebru, S. Gopalani, A. Hailu, M. Horino, N. Horita, A. Husseini, I. Huybrechts, M. Inoue, F. Islami, M. Jakovljevic, S. James, M. Javanbakht, S. H. Jee, A. Kasaeian, M. S. Kedir, Y. S. Khader, Y. H. Khang, D. Kim, J. Leigh, S. Linn, R. Lunevicius, H. M. A. El Razek, R. Malekzadeh, D. C. Malta, W. Marcenes, D. Markos, Y. A. Melaku, K. G. Meles, W. Mendoza, D. T. Mengiste, T. J. Meretoja, T. R. Miller, K. A. Mohammad, A. Mohammadi, S. Mohammed, M. Moradi-Lakeh, G. Nagel, D. Nand, Q. Le Nguyen, S. Nolte, F. A. Ogbo, K. E. Oladimeji, E. Oren, M. Pa, E. K. Park, D. M. Pereira, D. Plass, M. Qorbani, A. Radfar, A. Rafay, M. Rahman, S. M. Rana, K. Soreide, M. Satpathy, M. Sawhney, S. G. Sepanlou, M. A. Shaikh, J. She, I. Shiue, H. R. Shore, M. G. Shrime, S. So, S. Soneji, V. Stathopoulou, K. Stroumpoulis, M. B. Sufiyan, B. L. Sykes, R. TabaresSeisdedos, F. Tadese, B. A. Tedla, G. A. Tessema, J. S. Thakur, B. X. Tran, K. N. Ukwaja, B. S. C. Uzochukwu, V. V. Vlassov, E. Weiderpass, M. Wubshet Terefe, H. G. Yebyo, H. H. Yimam, N. Yonemoto, M. Z. Younis, C. Yu, Z. Zaidi, M. E. S. Zaki, Z. M. Zenebe, C. J. L. Murray and M. Naghavi, JAMA Oncol., 2017, 3, 524-548.

3 J. Mann, Nat. Rev. Cancer, 2002, 2, 143-148.

4 A. Bhanot, R. Sharma and M. N. Noolvi, Phytomedicine, 2011, 3, 09.

5 J. Du and X. L. Tang, J. Cancer Res. Ther., 2014, 10(suppl. 1), 27-37.

6 S. Patel and A. Goyal, 3 Biotech, 2012, 2, 1-15.

7 G. L. Lincoff, National Audubon Society Field Guide to North American Mushrooms, Alfred A. Knopf, New York, 1995.

8 D. Arora, Mushrooms Demystified: A Comprehensive Guide to the Fleshy Fungi, Ten Speed Press, 1986.

9 N. S. Weber, A. H. Smith and D. Guravich, A field guide to southern mushrooms, University of Michigan Press, 1985.

$10 \mathrm{~J}$. Ying, Icons of medicinal fungi from China, Science Press, 1987.

11 R. Marumoto, C. Kilpert and W. Steglich, Z. Naturforsch., C: J. Biosci., 1986, 41, 363-365.

12 C. J. Duncan, M. Cuendet, F. R. Fronczek, J. M. Pezzuto, R. G. Mehta, M. T. Hamann and S. A. Ross, J. Nat. Prod., 2003, 66, 103-107.

13 M. Gill, Nat. Prod. Rep., 1994, 11, 67-90.

14 D. N. Quang, T. Hashimoto, M. Nukada, I. Yamamoto, M. Tanaka, S. Takaoka and Y. Asakawa, Chem. Pharm. Bull., 2003, 51, 330-332.

15 C. S. Kim, E. Moon, S. U. Choi, S. Y. Kim, K. R. Lee and K. H. Kim, J. Antibiot., 2015, 68, 414-416.

16 S. R. Lee, K. Jung, H. J. Noh, Y. J. Park, H. L. Lee, K. R. Lee, K. S. Kang and K. H. Kim, Bioorg. Med. Chem. Lett., 2015, 25, 5712-5715.

17 H. J. Noh, H. H. Yang, G. S. Kim, S. E. Lee, D. Y. Lee, J. H. Choi, S. Y. Kim, E. S. Lee, S. H. Ji, K. S. Kang, H. J. Park, J. R. Kim and K. H. Kim, J. Enzyme Inhib. Med. Chem., 2015, 30, 934-940.
18 S. Lee, G. Tamayo-Castillo, C. Pang, J. Clardy, S. Cao and K. H. Kim, Bioorg. Med. Chem. Lett., 2016, 26, 2438-2441.

19 S. R. Lee, S. Lee, E. Moon, H. J. Park, H. B. Park and K. H. Kim, Bioorg. Chem., 2017, 70, 94-99.

20 W. S. Suh, S. R. Lee, C. S. Kim, E. Moon, S. Y. Kim, S. U. Choi, K. S. Kang, K. R. Lee and K. H. Kim, J. Chem. Res., 2016, 40, 156-159.

21 T. Mosmann, J. Immunol. Methods, 1983, 65, 55-63.

22 S. Elmore, Toxicol. Pathol., 2007, 35, 495-516.

23 A. T. Koparal, Z. Naturforsch., C: J. Biosci., 2015, 70, 159-164.

24 S. H. Kaufmann, S. Desnoyers, Y. Ottaviano, N. E. Davidson and G. G. Poirier, Cancer Res., 1993, 53, 3976-3985.

25 J. Wang, G. Li, N. Lv, L. Gao, L. Cao, L. Shen and J. Si, Arch. Pharmacal Res., 2016, 39, 747-754.

26 A. Pulte, S. Wagner, H. Kogler and P. Spiteller, J. Nat. Prod., 2016, 79, 873-878.

27 M. Clericuzio, S. Tabasso, M. A. Bianco, G. Pratesi, G. Beretta, S. Tinelli, F. Zunino and G. Vidari, J. Nat. Prod., 2006, 69, 1796-1799.

28 D. Fernando, A. Adhikari, C. Nanayakkara, E. D. de Silva, R. Wijesundera and P. Soysa, BMC Complementary Altern. Med., 2016, 16, 484.

29 K. H. Kim, E. Moon, S. U. Choi, S. Y. Kim and K. R. Lee, J. Nat. Prod., 2013, 76, 845-851.

30 Y. S. Lee, Y. H. Kim, E. K. Shin, D. H. Kim, S. S. Lim, J. Y. Lee and J. K. Kim, J. Ethnopharmacol., 2010, 131, 56-62.

31 H. Y. Huang, S. Y. Chieh, T. K. Tso, T. Y. Chien, H. T. Lin and Y. C. Tsai, J. Ethnopharmacol., 2011, 133, 460-466.

32 T. Mitsudomi, S. Steinberg, M. Nau, D. Carbone, D. D'amico, S. Bodner, H. Oie, R. Linnoila, J. Mulshine and J. Minna, Oncogene, 1992, 7, 171-180.

33 M. Rämet, K. Castrén, K. Järvinen, K. Pekkala, T. Turpeenniemi-Hujanen, Y. Soini, P. Pääkkö and K. Vähäkangas, Carcinogenesis, 1995, 16, 2117-2124.

34 P. S. Moore, B. Sipos, S. Orlandini, C. Sorio, F. X. Real, N. R. Lemoine, T. Gress, C. Bassi, G. Klöppel and H. Kalthoff, Virchows Arch., 2001, 439, 798-802.

35 M. Muller, S. Strand, H. Hug, E. M. Heinemann, H. Walczak, W. J. Hofmann, W. Stremmel, P. H. Krammer and P. R. Galle, J. Clin. Invest., 1997, 99, 403-413.

36 S. Kanokmedhakul, K. Kanokmedhakul, T. Prajuabsuk, K. Soytong, P. Kongsaeree and A. Suksamrarn, Planta Med., 2003, 69, 568-571.

37 O. Karaosmanoglu, H. Sivas, T. Tay and A. O. Turk, J. Biotechnol., 2015, 208, S95.

38 Y. A. Lazebnik, S. H. Kaufmann, S. Desnoyers, G. G. Poirier and W. C. Earnshaw, Nature, 1994, 371, 346-347.

39 D. W. Nicholson, A. Ali, N. A. Thornberry, J. P. Vaillancourt, C. K. Ding, M. Gallant, Y. Gareau, P. R. Griffin, M. Labelle, Y. A. Lazebnik, et al., Nature, 1995, 376, 37-43.

40 M. Los, I. Herr, C. Friesen, S. Fulda, K. Schulze-Osthoff and K. M. Debatin, Blood, 1997, 90, 3118-3129.

41 M. Los, S. Wesselborg and K. Schulze-Osthoff, Immunity, 1999, 10, 629-639.

42 F. Heidebrecht, A. Heidebrecht, I. Schulz, S. E. Behrens and A. Bader, J. Immunol. Methods, 2009, 345, 40-48. 